\title{
Current rehabilitation practices in intensive care units: a preliminary survey by the Japanese Society of Education for Physicians and Trainees in Intensive Care (JSEPTIC) Clinical Trial Group
}

\author{
Shunsuke Taito ${ }^{1}$, Masamitsu Sanui ${ }^{2^{*}}$ (1), Hideto Yasuda ${ }^{3}$, Nobuaki Shime ${ }^{4}$, Alan Kawarai Lefor ${ }^{5}$ and Japanese Society \\ of Education for Physicians and Trainees in Intensive Care (JSEPTIC) Clinical Trial Group ${ }^{6}$
}

\begin{abstract}
We conducted an internet survey targeting healthcare providers in intensive care units (ICUs) in Japan and received 318 responses. Eighteen percent of respondents replied that full-time physical therapists (PTs) exist in their ICUs. Practicing sitting upright or sitting in a chair is frequently performed, while standing and walking are occasionally performed for patients undergoing mechanical ventilation. However, only $16 \%$ of respondents use staged rehabilitation protocols. This preliminary survey suggests that full-time involvement of PTs in the ICU and introduction of rehabilitation protocols may not be common in Japanese ICUs.
\end{abstract}

Keywords: Rehabilitation, Physical therapist, Intensive care unit, Rehabilitation protocol, Early mobilization, Questionnaire survey

\section{To the editor}

In 2009, Schweickert et al. [1] first reported that early rehabilitation intervention significantly improved physical and mental function of critically ill patients. Since then, a substantial number of studies have shown the efficacy and safety of early rehabilitation and mobilization in the intensive care unit (ICU) [2, 3]. However, the criteria for determining the timing of initiation and suspension of rehabilitation in ICUs vary among studies, and the existence of standard rehabilitation protocols and the levels of physical therapist (PT) involvement for early mobilization are not yet ubiquitous, even in the USA [4]. It is not surprising that high-quality investigations have not yet been performed to describe the current practice of physical therapy in ICUs in Japan. Therefore, we conducted a

\footnotetext{
* Correspondence: msanui@mac.com

${ }^{2}$ Department of Anesthesiology and Critical Care Medicine, Jichi Medical University Saitama Medical Center, 1-847 Amanuma, Omiya-ku, Saitama, Saitama 330-8503, Japan

Full list of author information is available at the end of the article
}

preliminary internet survey investigating current practice patterns of physical therapy in Japanese ICUs.

Between January 13 and January 25 in 2016, anonymous questionnaires were distributed to physicians, nurses, PTs, occupational therapists (OTs), and speech therapists (STs), via the website of the Japanese Society of Education for Physicians and Trainees in Intensive Care (JSEPTIC) [5]. In this survey, rehabilitation was defined as any one of the following activities: passive exercise motion, neuromuscular electrical stimulation, respiratory muscle training, use of a cycle ergometer, practicing sitting upright or sitting in a chair, standing, and walking conducted for a patient admitted to an ICU.

Of the 318 respondents, $39(12.3 \%)$ are doctors, 97 (30.5\%) are nurses, 175 (55.0 \%) are PTs, OTs, or STs, and $7(2.2 \%)$ are clinical engineers or pharmacists. Institutional ICU staffing patterns of the respondents were categorized as closed ICUs (23 respondents, $7.2 \%$ ), ICUs with mandatory critical care consultation (102, $32.1 \%)$, ICUs with elective critical care consultation $(68,21.4 \%)$, ICUs with no critical care physician $(110,34.6 \%)$, and 


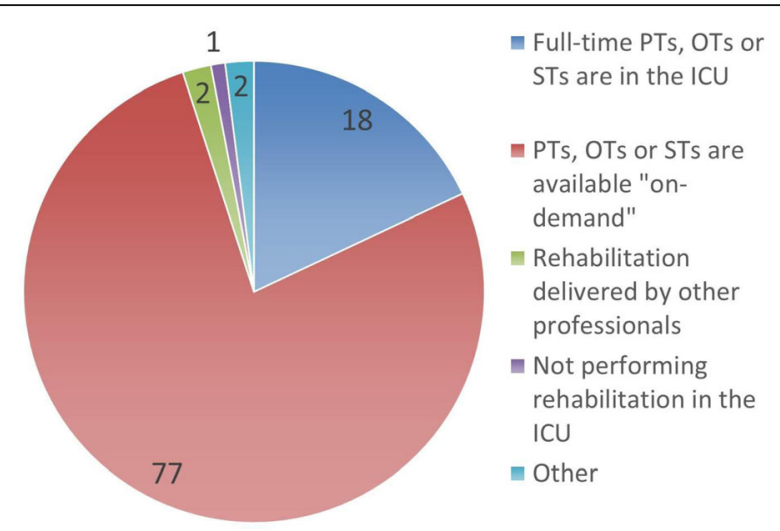

Fig. 1 Involvement of therapists in rehabilitation in ICUs. PTs physical therapists, OTs occupational therapists, STS speech therapists

unknown (15, $4.7 \%)$. Fifty-seven respondents (17.9 \%) responded that full-time PTs, OTs, or STs are involved in their ICUs, while 245 respondents $(77.0 \%)$ responded that they are involved "on-demand" (Fig. 1). Joint range of motion exercises, practicing sitting upright or sitting in a chair, and standing are frequently performed rehabilitation exercises for patients undergoing mechanical ventilation (Table 1). Respiratory muscle training and walking are occasionally performed. The majority of respondents answered that they never perform neuromuscular electrical stimulation or use a cycle ergometer. Despite the frequent conduct of sitting, standing, and walking in patients undergoing mechanical ventilation, only 51 respondents $(16.0 \%)$ replied that protocols for conducting staged rehabilitation for patients in the ICU exist (Fig. 2). Two hundred and thirty-six (74.2\%) answered that no such protocols exist, while approximately half indicated that protocols are currently under consideration. The decision to initiate rehabilitation in various patient conditions depends on the profession of the respondent and whether

Table 1 Frequency of rehabilitation exercises performed for patients undergoing mechanical ventilation

\begin{tabular}{lllll}
\hline & $\begin{array}{l}\text { Frequently, } \\
N(\%)\end{array}$ & $\begin{array}{l}\text { Occasionally, } \\
N(\%)\end{array}$ & $\begin{array}{l}\text { Never, } \\
N(\%)\end{array}$ & $\begin{array}{l}\text { Unknown, } \\
N(\%)\end{array}$ \\
\hline $\begin{array}{l}\text { Joint range of } \\
\text { motion exercises }\end{array}$ & $249(78.3)$ & $61(19.2)$ & $7(2.2)$ & $1(0.3)$ \\
$\begin{array}{l}\text { Sitting upright or } \\
\text { sitting in a chair }\end{array}$ & $207(65.1)$ & $91(28.6)$ & $16(5.0)$ & $4(1.3)$ \\
$\begin{array}{l}\text { Standing } \\
\text { Respiratory muscle } \\
\text { training }\end{array}$ & $134(42.1)$ & $134(42.1)$ & $41(12.9)$ & $9(2.9)$ \\
$\begin{array}{l}\text { Walking } \\
\begin{array}{l}\text { Neuromuscular } \\
\text { electrical stimulation }\end{array}\end{array}$ & $4(155(48.7)$ & $46(14.5)$ & $12(3.8)$ \\
Cycle ergometer & $7(2.2)$ & $42(13.2)$ & $248(78.0)$ & $21(6.6)$ \\
\hline
\end{tabular}

Frequencies reported above may include multiple responders from a single institution

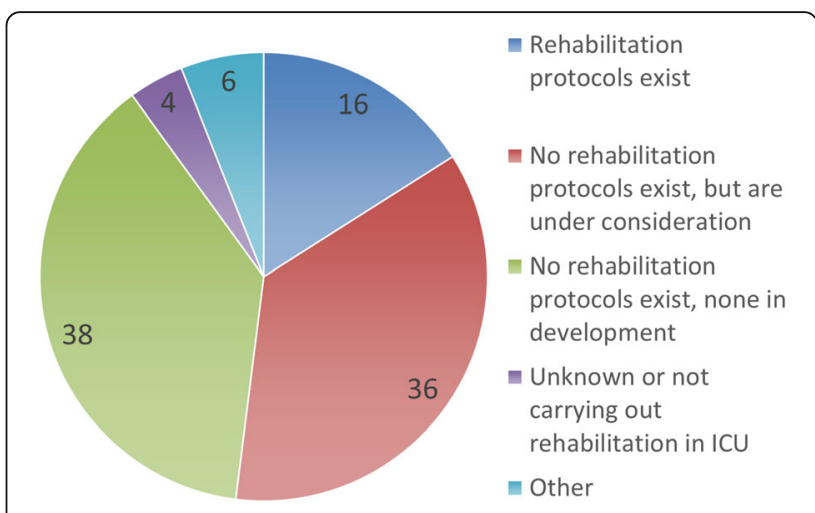

Fig. 2 Existence of rehabilitation protocols

they are actively involved in rehabilitation practice or not (data not shown).

This preliminary web-based survey suggests that fulltime involvement of PTs, OTs, or STs in the ICU and introduction of rehabilitation protocols may not be common in Japanese ICUs. In Europe, 75 \% of ICUs had at least one PT working exclusively in the ICU [6]. Most ICUs in Australia also have at least one senior PT on staff [7]. This study suggests that rehabilitation may be provided "on-demand" in most ICUs in Japan. Recently, a consensus on active mobilization, including the criteria for determining when to start or suspend an intervention for patients undergoing mechanical ventilation, has been reported [8]. Risk stratification and safety standards regarding physical therapy and rehabilitation have also been reported [9]. However, this study suggests that in a majority of Japanese ICUs, rehabilitation practice may be performed on an individual-therapist basis, not following established protocols. It has been reported that following physical therapy protocols by an exclusively allocated PT decreased endotracheal intubation and reintubation rates in the ICU and hospital length of stay [10]. A study investigating the effect of protocolized rehabilitation by full-time PTs on patient outcomes is needed. This preliminary survey was made by voluntary participation of an individual respondent who viewed the website of the ISEPTIC Clinical Trial Group. The institutional information of individual respondents was not obtained, making it possible to have multiple respondents from one institution, not reflecting regional disparities in practice. It is acknowledged that selection bias of participants could result from an internet survey. Further studies are needed to clarify these limitations.

\section{Abbreviations}

ICU: Intensive care unit; OTs: Occupational therapists; PTs: Physical therapists; STs: Speech therapists 


\section{Funding}

There is no funding to be declared.

\section{Availability of data and materials}

The datasets supporting the conclusions of this article are available in the Japanese Society of Education for Physicians and Trainees in Intensive Care (http://www.jseptic.com/rinsho/questionnaire_490225.pdf).

\section{Authors' contributions}

ST and MS wrote the manuscript. HY, NS, AKL, and the JSEPTIC Clinical Trial Group helped in critically revising the manuscript. All authors read and approved the final manuscript.

\section{Competing interests}

The authors declare that they have no competing interests.

\section{Consent for publication}

Not applicable

\section{Ethics approval and consent to participate}

This survey was based on the requirements of the Declaration of Helsinki, and informed consent was obtained from all participants.

\section{Author details}

'Division of Rehabilitation, Department of Clinical Practice and Support, Hiroshima University Hospital, Hiroshima, Japan. ${ }^{2}$ Department of Anesthesiology and Critical Care Medicine, Jichi Medical University Saitama Medical Center, 1-847 Amanuma, Omiya-ku, Saitama, Saitama 330-8503, Japan. ${ }^{3}$ Department of Intensive Care Medicine, Kameda Medical Center, 929, Higashi-cho, Kamogawa, Chiba 296-8602, Japan. ${ }^{4}$ Department of Emergency and Critical Care Medicine, Hiroshima University, 1-2-3, Kasumi, Minami-ku, Hiroshima 734-8551, Japan. ${ }^{5}$ Department of Surgery, Jichi Medical University,

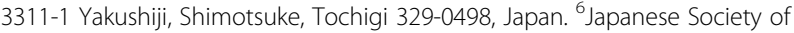
Education for Physicians and Trainees in Intensive Care, 3-3-11 Hongo, Bunkyo-ku, Tokyo 113-0033, Japan.

Received: 4 September 2016 Accepted: 24 October 2016 Published online: 28 October 2016

\section{References}

1. Schweickert WD, Pohlman MC, Pohlman AS, Nigos C, Pawlik AJ, Esbrook CL, et al. Early physical and occupational therapy in mechanically ventilated, critically ill patients: a randomised controlled trial. Lancet. 2009;373:1874-82.

2. Burtin C, Clerckx B, Robbeets C, Ferdinande P, Langer D, Troosters T, et al. Early exercise in critically ill patients enhances short-term functional recovery. Crit Care Med. 2009;37:2499-505.

3. Schaller SJ, Anstey M, Blobner M, Edrich T, Grabitz SD, Gradwohl-Matis I, et al. Early, goal-directed mobilisation in the surgical intensive care unit: a randomised controlled trial. Lancet. 2016;388:1377-88.

4. Bakhru RN, Wiebe DJ, McWilliams DJ, Spuhler VJ, Schweickert WD. An environmental scan for early mobilization practices in U.S. ICUs. Crit Care Med. 2015:43:2360-9

5. Japanese Society of Education for Physicians and Trainees in Intensive Care http://www.jseptic.com/en/ (2008). Accessed 23 July 2016.

6. Norrenberg M, Vincent JL. A profile of European intensive care unit physiotherapists. European Society of Intensive Care Medicine. Intensive Care Med. 2000;26:988-94

7. Skinner EH, Berney S, Warrillow S, Denehy L. Rehabilitation and exercise prescription in Australian intensive care unit. Physiotherapy. 2008;94:220-9.

8. Hodgson CL, Stiller K, Needham DM, Tipping CJ, Harrold M, Baldwin CE, et al. Expert consensus and recommendations on safety criteria for active mobilization of mechanically ventilated critically ill adults. Crit Care. 2014;18:658.

9. Sommers J, Engelbert RH, Dettling-Ihnenfeldt D, Gosselink R, Spronk PE, Nollet $F$, et al. Physiotherapy in the intensive care unit: an evidence-based, expert driven, practical statement and rehabilitation recommendations. Clin Rehabil. 2015;29:1051-63.

10. Hanekom SD, Louw Q, Coetzee A. The way in which a physiotherapy service is structured can improve patient outcome from a surgical intensive care: a controlled clinical trial. Crit Care. 2012;16:R230

\section{Submit your next manuscript to BioMed Central and we will help you at every step:}

- We accept pre-submission inquiries

- Our selector tool helps you to find the most relevant journal

- We provide round the clock customer support

- Convenient online submission

- Thorough peer review

- Inclusion in PubMed and all major indexing services

- Maximum visibility for your research

Submit your manuscript at www.biomedcentral.com/submit
) Biomed Central 